\title{
Age related differences in cannabis use and subjective effects in a large population- based survey of adult athletes
}

\author{
Joanna S. Zeiger ${ }^{1 *}$ (D), William S. Silvers ${ }^{1,2}$, Edward M. Fleegler ${ }^{1,3}$ and Robert S. Zeiger ${ }^{1,4}$
}

\begin{abstract}
Background: There is a paucity of information regarding cannabis use behaviors in adult community-based athletes as most research in athletes has focused on misuse of cannabis in elite, adolescent, university-based athletes. We aimed to determine whether age related differences exist in patterns of cannabis use and subjective effects to cannabis in adult athletes.

Methods: The Athlete PEACE Survey used mainly social media and email blasts to recruit and SurveyGizmo to collect data. Cannabis patterns of use (duration of use, frequency of use, routes of administration, cannabinoid used, concurrent use with exercise), benefits, and adverse effects were reported. Age was reported by decade from 21 to $\geq 60$. Age trends in cannabis use patterns and subjective effects were assessed using linear trend analysis.

Results: Of the 1161 participants, 301 (26\%) athletes currently used cannabis. Younger athletes compared to older athletes reported significantly more positive and adverse subjective effects to cannabis, used cannabis longer, and used both tetrahydrocannabinol and cannabidiol for medical and recreational purposes. Younger athletes used cannabis concurrently with exercise more often than older athletes and consumed edibles, vaporized, and smoked more than older athletes.

Conclusions: We found age-related cannabis patterns of use and subjective effects to cannabis. Concerns about cannabis mis-use and abuse in athletes maybe overstated with the potential benefits (improved sleep, decreased anxiety, less pain) outweighing the adverse effects (increased anxiety, increased appetite, difficulty concentrating).
\end{abstract}

Keywords: Marijuana, Medical marijuana, Adults, Sports medicine

\section{Background}

Athletes are known as early adopters of new and innovative modalities to aid in recovery and performance (Conrad et al. 2019; Caine et al. 2012), particularly since pain, insomnia, and anxiety are common and difficult to solve problems among athletes (Hainline et al. 2017; Mann et al. 2007; Halson 2014). Cannabis is a modality that has reportedly improved symptoms among sufferers of pain, insomnia, and anxiety (Stith et al. 2019; Mannucci et al. 2017), but has rarely been studied in the context of adult athlete use. Historically, cannabis use in athletes has typically been studied in the framework of abuse among adolescent, university, and elite athletes

\footnotetext{
* Correspondence: joannazeiger@comcast.net

'Canna Research Group, 3996 Savannah Ct., Boulder, CO 80301, USA

Full list of author information is available at the end of the article
}

(Ware et al. 2018; Buckman et al. 2011; Peretti-Watel et al. 2003a). More recent studies have suggested that athletes are using cannabis to improve mood and enjoyment of exercise (YorkWilliams et al. 2019), but patterns of use and positive and adverse effects to cannabis in adult athletes is largely unknown.

The NCAA found that $30.3 \%$ of student athletes consumed cannabis with social and recreational reasons as the primary reasons for use (Brisola-Santos et al. 2016). International studies reported that current cannabis use ranged from 2.7 to $23.0 \%$ in elite athletes (Brisola-Santos et al. 2016). Studies in elite and collegiate athletes found the highest use in males, winter sport athletes, and teenage females who compete on an international level (Brisola-Santos et al. 2016). These studies did not measure self-reported effects to cannabis.

(C) The Author(s). 2019 Open Access This article is distributed under the terms of the Creative Commons Attribution 4.0 International License (http://creativecommons.org/licenses/by/4.0/), which permits unrestricted use, distribution, and reproduction in any medium, provided you give appropriate credit to the original author(s) and the source, provide a link to the Creative Commons license, and indicate if changes were made. The Creative Commons Public Domain Dedication waiver (http://creativecommons.org/publicdomain/zero/1.0/) applies to the data made available in this article, unless otherwise stated. 
It is critical to unravel the self-reported effects to cannabis (subjective effects) as cannabis use increases due to legalization and consumption for medical purposes. Measuring subjective effects and relating them to patterns of use, cannabinoids used, routes of administration, and age-related differences can provide insights for athletes, consumers, and medical professionals to develop best practices for using cannabis to treat medical conditions. Subjective effects have been collected to understand many facets of cannabis use and abuse (Haberstick et al. 2011; Scherrer et al. 2009). In adolescents, cannabis subjective effects are a predictor of downstream use and abuse (Haberstick et al. 2011; Zeiger et al. 2010), while in laboratory settings subjective effects are used to understand the dosing effects of tetrahydrocannabinol (THC) (Curran and Brignell 2002; Schwope et al. 2012). A randomized-controlled clinical trial in Australian cannabis users and non-users aged 21-44, evaluated CBD alone, THC alone, THC combined with high CBD, THC combined with low CBD, and a placebo (Solowij et al. 2019). The study concluded that low doses of CBD in combination with THC enhanced the effects of THC while high doses of CBD in combination with THC reduced the effects of THC (Solowij et al. 2019), indicating that the dosing effects of cannabinoids changed the perceived effects of cannabis use. Longitudinal studies of subjective effects to cannabis have shown that initial positive and adverse responses to cannabis in adolescence predict cannabis use behavior in young adulthood.

A review of subjective effects to cannabis found that relaxation was the most commonly reported item (Green et al. 2003), but paradoxical impacts of cannabis can occur in which opposing effects can be experienced within individuals and between individuals (Green et al. 2003; Zeiger et al. 2012). That individuals can experience both positive and adverse effects to cannabis may partially be due to the lack of information on optimal dosing and/or the possible inverted U-shaped doseresponse curve on efficacy at low doses and adverse effects at high doses (Solowij et al. 2019; Martin-Santos et al. 2012; Zuardi et al. 2017).

Age-effects for past month cannabis use exist; the highest use was observed in 18-25-year old's (17.3\%) and the lowest use among those over 50 (2.0\%) (Haug et al. 2017)\. Younger cannabis users showed a higher prevalence of cannabis use disorders and middle-aged and older adults reporting using cannabis medically (Haug et al. 2017). A cross-sectional study of age-related patterns of cannabis use in dispensary patients found that $75 \%$ were males, the frequency of cannabis use did not differ across ages but the amount consumed differed with the younger cannabis users (18-21) consuming a larger quantity of cannabis than middle-aged users (31-
50) and older users (51-74). Routes of administration differed by age group, with younger cannabis users showing a preference for vaping, older age groups using oral administration, and the oldest age group reporting medical cannabis use more frequently than the younger ages (Haug et al. 2017).

Patterns of use are related to subjective effects to cannabis (Daniulaityte et al. 2018; Ware et al. 2005). Frequency of use, route of administration, and type of cannabinoid used all impact the effects to cannabis (Stith et al. 2019; Sexton et al. 2016; Stith et al. 2018). A comprehensive study of medical cannabis patients found that the primary route of administration was inhalation (84\%); oral administration was only 8 , and $0.6 \%$ used topicals (Peretti-Watel et al. 2003b).

Age-related subjective effects to cannabis and patterns of cannabis use in adults are poorly elucidated particularly in adult community-based athletes. As cannabis becomes legal in more states, cannabis use will continue to rise, both for medical and recreational purposes. It is important to understand the age-related differences in cannabis use among adult athletes, particularly for those athletes who want to receive the most benefit with lowest risk, for physicians who manage these athletes, and for health policy makers who develop guidelines for cannabis use among athletes and the general population.

Our Athlete Pain, Exercise, And Cannabis Experience (PEACE) Survey study presently in review (Buckman et al. 2011) characterized cannabis use using cluster analysis in community-based athletes $\geq 21$ years of age. The objectives of the present secondary analysis of the Athlete PEACE Survey study were to determine in adult athletes (1) whether age-related differences occur in patterns of cannabis use (i.e. frequency and duration of use, route of administration, reason for use, primary cannabinoid used, timing around exercise) exist and (2) whether positive and adverse subjective effects to cannabis differ by age. We hypothesized that there would be age trends in cannabis patterns of use and subjective effects to cannabis.

\section{Methods}

This cross-sectional quantitative survey study used a convenience sample (Zeiger et al. 2019a). The study was approved with waiver of written consent by Solutions IRB (http://www.solutionsirb.com). Participants were assured confidentiality. Implied consent was provided by survey completion. Participants were required to be, (1) ages 21 years or older, (2) a self-declared athlete of any sport, and (3) English speaking with no other inclusions or exclusions. The survey was administered on SurveyGizmo (https://www.surveygizmo.com) between 6 September 2018 and 7 December 2018. Social media (Facebook, Twitter, LinkedIn, athlete forums), email 
communications, and flyers posted in specialty sports stores in Boulder and Baltimore were used for subject recruitment, allowing for large scale targeting of potential participants in a relatively short time (Zeiger and Zeiger 2018). 1161 (91.1\%) of the 1274 athletes taking the survey completed it (see Additional file 1 for survey questions).

Demographics were collected and reported in Additional file 2: Table S1 (Zeiger et al. 2019b). Athletes were asked whether they ever used marijuana and "In the past two weeks, have you used marijuana [including THC and/or cannabidiol (CBD)]?" Participants who responded "yes" to using marijuana in the past 2 weeks were asked if they primarily used THC, CBD, or both THC and CBD. Questions about positive (Table 2, 9 items) and adverse (Table 3, 8 items) subjective effects from cannabis use were included. Participants were able to endorse as many of the items that applied to them. Routes of administration were also measured; participants were able to choose as many as they used. This was a secondary analysis of a primary cluster analysis study. Sample size justifications for cluster analysis are the following: A systematic analysis of sample sizes for cluster analyses reviewed 243 cluster analyses. The study found that the median sample size for the cluster analyses was 293 participants, similar to the 301 participants used in the cluster analysis of the primary study (Online and Dolnicar 2002). A simulation study found valid solutions for cluster analysis with samples as small as 20 (Henry et al. 2015). Our results from the primary analysis manuscript showed that the present sample size was adequate to clearly cluster the participants into 3 clinically distinct clusters (Zeiger et al. 2019a).

Descriptive analyses were conducted using SPSS v23. Three hundred one of the 1161 (25.9\%) survey completers were current cannabis users and are the subject for this secondary analysis which examines the age-related differences of cannabis use. The Jonckheere-Terpstra procedure, a non-parametric rank based trend test in SPSS, was performed to determine whether there was a statistically significant linear trend between the ordinal variable of age by decade and the patterns of use and subjective effects (Bewick et al. 2004). The null hypothesis of the study states that there will be no age-related differences in cannabis patterns of use and subjective effects to cannabis as measured by the Jonckheer-Terpstra procedure. $P$ values $<0.05,2$ sided, was set for significance.

\section{Results}

Of current cannabis users $(n=301), 15.6 \%$ were $21-29$ $(n=47), 24.6 \%$ were $30-39(n=74), 26.9 \%$ were $40-49$ $(n=81), 20.3 \%$ were $50-59(n=61)$ and $12.6 \%$ were $\geq 60$ years of age $(n=38)$. The sample was $60.3 \%$ male and 89.1\% Caucasian with no difference in age distribution by gender or ethnicity (Additional file 2: Table S1).
Demographics, sports demographics, attitudes about cannabis and patterns of cannabis use by primary sport are shown in Additional file 2: Table S1. The "other" sports category was comprised of swimming, winter sports, hiking, walking, climbing, yoga, trail running, and strength sports. The "other" sport category reported the most frequent cannabis use, but there were no differences by sport for reasons for cannabis use, duration of cannabis use, and cannabinoid used. Triathletes exercised the greatest number of days per week for the most hours per week and more frequently reported being "professional" or a serious/competitive amateur. Among current cannabis users, $61.1 \%$ indicated that they use cannabis for pain with no significant difference in use for pain by sport. Athletes in the "other" sports category (36.5\%) reported using cannabis within $1 \mathrm{~h}$ of exercising more often than the other sports; there were no differences for cannabis use during exercise or within $1 \mathrm{~h}$ after exercise by sport (Additional file 3: Table S2).

\section{Patterns of use (Table 1)}

Younger athletes used both THC and CBD $(p=$ $0.009)$ and older athletes used mainly CBD only $(p<0.001)$. A significant trend was seen for reason for use with younger athletes using cannabis more for recreational $(p=0.002)$ and both THC and CBD for medical and recreational reasons $(p=0.009)$, while older athletes used cannabis for medical purposes $(\mathrm{p}<$ 0.001 ). A longer duration of use trended towards younger athletes $(p<0.001)$, but frequency of use did not differ by age. Younger athletes consumed edibles, smoked, and vaporized more often than older athletes (all $p<0.001$ ); older athletes used oil/tinctures at a higher rate than younger athletes $(p=0.003)$. Overall, $26.2 \%$ of the sample reported cannabis use within $1 \mathrm{~h}$ before starting exercise, 9\% indicated cannabis use during exercise, and $33.2 \%$ indicated they use cannabis within $1 \mathrm{~h}$ after exercise. There were significant age trends for cannabis use prior to exercise and after exercise with younger athletes using cannabis more often during those time periods than older athletes $(\mathrm{p}<0.001)$. Athletes were asked whether they used cannabis within $1 \mathrm{~h}$ before exercise, during exercise, and within $1 \mathrm{~h}$ after exercise. Cannabis use during exercise was not common, ranging from $4.3 \%$ in athletes $21-29$ to $11.1 \%$ in athletes $40-49$; there was not a significant trend for age for use during exercise. Athletes primarily used cannabis within one of hour of exercise for improving focus $(46.3 \%)$ and improving activity enjoyment (47.8\%). Athletes used cannabis within one-hour post-exercise to aid in recovery $(75.4 \%)$, for pain management (67.9\%) and for sleep enhancement (65.7\%) (Additional file 3: Table S2). 
Table 1 Cannabis patterns of use by decade in community-based athletes

\begin{tabular}{|c|c|c|c|c|c|c|c|}
\hline \multirow[t]{2}{*}{ Pattern of use } & Category & 21 to $29(n=47)$ & 30 to $39(n=74)$ & 40 to $49(n=81)$ & 50 to $59(n=61)$ & $\geq 60(n=38)$ & $P$ value for trend \\
\hline & \multicolumn{7}{|l|}{ N (\%) } \\
\hline \multirow[t]{3}{*}{ Cannabinoid used } & $\mathrm{THC}$ & $10(21.3)$ & $19(25.7)$ & 16 (19.8) & $10(16.4)$ & $6(15.8)$ & 0.21 \\
\hline & CBD & $9(19.1)$ & 16 (21.6) & $27(33.3)$ & $28(45.9)$ & $21(55.3)$ & $<0.001$ \\
\hline & THC and CBD & $28(59.6)$ & $39(52.7)$ & $38(46.9)$ & $23(37.7)$ & $11(28.9)$ & 0.009 \\
\hline \multirow[t]{3}{*}{ Reason for use } & Medical & $4(8.5)$ & $15(20.3)$ & 28 (34.6) & $31(50.8)$ & $21(55.3)$ & $<0.001$ \\
\hline & Recreational & $21(44.7)$ & $23(31.1)$ & $23(28.4)$ & $15(24.6)$ & $5(13.2)$ & 0.002 \\
\hline & Both & $22(46.8)$ & 36 (48.6) & $30(37.0)$ & 15 (24.6) & $12(31.6)$ & 0.004 \\
\hline Duration & $>3$ years & $30(63.8)$ & $41(55.4)$ & $37(45.7)$ & $21(34.4)$ & $18(47.4)$ & $<0.001$ \\
\hline Frequency & $\geq 4$ times/week & $12(25.5)$ & 39 (52.7) & $33(40.7)$ & $20(32.8)$ & $13(34.2)$ & 0.20 \\
\hline \multirow{7}{*}{$\begin{array}{l}\text { Routes of } \\
\text { administration }\end{array}$} & Edible & $31(66.0)$ & 38 (51.4) & $46(56.8)$ & $18(29.5)$ & $14(36.8)$ & $<0.001$ \\
\hline & Vaporize & $25(53.2)$ & $34(45.9)$ & $28(34.6)$ & $14(23.0)$ & $8(21.1)$ & $<0.001$ \\
\hline & Smoke & $23(48.9)$ & $35(47.3)$ & $26(32.1)$ & $15(24.6)$ & $8(21.1)$ & $<0.001$ \\
\hline & Oil/tincture & $17(36.2)$ & $24(32.4)$ & $35(43.2)$ & $31(50.8)$ & $23(60.5)$ & 0.003 \\
\hline & Topical & 15 (31.9) & $23(31.1)$ & $29(35.8)$ & $22(36.1)$ & $13(34.2)$ & 0.57 \\
\hline & Capsule & $7(14.9)$ & $8(10.8)$ & $13(16.0)$ & $10(16.4)$ & $1(2.6)$ & 0.51 \\
\hline & Spray & $2(4.3)$ & $5(6.8)$ & $3(3.7)$ & $3(4.9)$ & $1(2.6)$ & 0.57 \\
\hline \multirow{7}{*}{$\begin{array}{l}\text { Routes of } \\
\text { administration }\end{array}$} & Edible & $31(66.0)$ & 38 (51.4) & $46(56.8)$ & $18(29.5)$ & $14(36.8)$ & $<0.001$ \\
\hline & Vaporize & $25(53.2)$ & 34 (45.9) & $28(34.6)$ & $14(23.0)$ & $8(21.1)$ & $<0.001$ \\
\hline & Smoke & $23(48.9)$ & 35 (47.3) & $26(32.1)$ & 15 (24.6) & $8(21.1)$ & $<0.001$ \\
\hline & Oil/tincture & $17(36.2)$ & $24(32.4)$ & $35(43.2)$ & $31(50.8)$ & $23(60.5)$ & 0.003 \\
\hline & Topical & 15 (31.9) & $23(31.1)$ & 29 (35.8) & $22(36.1)$ & $13(34.2)$ & 0.57 \\
\hline & Capsule & $7(14.9)$ & $8(10.8)$ & $13(16.0)$ & $10(16.4)$ & $1(2.6)$ & 0.51 \\
\hline & Spray & $2(4.3)$ & $5(6.8)$ & $3(3.7)$ & $3(4.9)$ & $1(2.6)$ & 0.57 \\
\hline \multirow[t]{3}{*}{ Timing of use } & $\begin{array}{l}\text { Within } 1 \mathrm{~h} \text { before } \\
\text { starting exercise }\end{array}$ & $14(29.8)$ & $25(33.8)$ & $21(25)$. & $13(21.3)$ & $6(15.8)$ & $<0.001$ \\
\hline & During exercise & $2(4.3)$ & $7(9.5)$ & $9(11.1)$ & $6(9.8)$ & $3(7.9)$ & 0.53 \\
\hline & $\begin{array}{l}\text { Within } 1 \mathrm{~h} \text { after } \\
\text { finishing exercise }\end{array}$ & $21(44.7)$ & $37(50.0)$ & $21(25.9)$ & $13(21.3)$ & $8(21.1)$ & $<0.001$ \\
\hline
\end{tabular}

Table 2 Endorsement of positive subjective effects to cannabis by decade in community-based athletes

\begin{tabular}{|c|c|c|c|c|c|c|}
\hline \multirow[t]{2}{*}{ Positive subject effects } & 21 to $29(N=47)$ & 30 to $39(N=74)$ & 40 to $49(N=81)$ & 50 to $59(N=61)$ & $\geq 60(n=38)$ & $P$ value for trend \\
\hline & \multicolumn{6}{|l|}{ N (\%) } \\
\hline Helps with sleep & $37(78.7)$ & $61(82.4)$ & $59(72.8)$ & $35(57.4)$ & $23(60.5)$ & 0.003 \\
\hline Calms me down & $36(76.6)$ & $59(79.7)$ & $37(45.7)$ & $26(42.6)$ & $18(47.4)$ & $<0.001$ \\
\hline Less pain & $32(68.1)$ & $54(73.0)$ & $56(69.1)$ & $37(60.7)$ & $28(73.7)$ & 0.48 \\
\hline Decreased anxiety & $30(63.8)$ & $52(70.3)$ & $44(54.3)$ & $25(41.0)$ & $13(34.2)$ & $<0.001$ \\
\hline Euphoria & $20(42.6)$ & $31(41.9)$ & $16(19.8)$ & $16(26.2)$ & $6(15.8)$ & $<0.001$ \\
\hline Decreased nausea & $17(36.2)$ & $22(29.7)$ & $11(13.6)$ & $7(11.5)$ & $3(7.9)$ & $<0.001$ \\
\hline Increased energy & $12(25.5)$ & $29(39.2)$ & $21(25.9)$ & $14(23.0)$ & $4(10.5)$ & 0.019 \\
\hline Fewer muscle spasms & $10(21.3)$ & $16(21.6)$ & $16(19.8)$ & $4(6.6)$ & $4(10.5)$ & 0.063 \\
\hline Improved athletic performance & $9(19.1)$ & $18(24.3)$ & $15(18.5)$ & $8(13.1)$ & $6(15.8)$ & 0.18 \\
\hline
\end{tabular}


Table 3 Endorsement of adverse subjective effects to cannabis by decade in community-based athletes

\begin{tabular}{|c|c|c|c|c|c|c|}
\hline \multirow[t]{2}{*}{ Negative subject effects } & 21 to $29(N=47)$ & 30 to $39(N=74)$ & 40 to $49(N=81)$ & 50 to $59(N=61)$ & $\geq 60(n=38)$ & $P$ value for trend \\
\hline & \multicolumn{6}{|l|}{ N (\%) } \\
\hline Anxiety & $21(44.7)$ & $23(31.1)$ & $11(13.6)$ & $7(11.5)$ & $1(2.6)$ & $<0.001$ \\
\hline Increased appetite & 18 (38.3) & $25(33.8)$ & $12(14.8)$ & $10(16.4)$ & $8(21.1)$ & 0.002 \\
\hline Difficulty concentrating & $14(29.8)$ & $12(16.2)$ & $10(12.3)$ & $8(13.1)$ & $6(15.8)$ & 0.063 \\
\hline Cardiovascular & $9(19.1)$ & $8(10.8)$ & $1(1.2)$ & $3(4.9)$ & $0(0.0)$ & $<0.001$ \\
\hline Respiratory & $8(17.0)$ & 19 (25.7) & $6(7.4)$ & $8(13.1)$ & $3(7.9)$ & 0.002 \\
\hline Gastrointestinal & $5(10.6)$ & $4(5.4)$ & $1(1.2)$ & $0(0.0)$ & $0(0.0)$ & 0.001 \\
\hline Worse athletic performance & $1(2.1)$ & $7(9.5)$ & $1(1.2)$ & $0(0.0)$ & $0(0.0)$ & 0.003 \\
\hline Skin reaction & $0(0.0)$ & $1(1.4)$ & $2(2.5)$ & $0(0.0)$ & $0(0.0)$ & 0.81 \\
\hline
\end{tabular}

\section{Positive subjective effects (Table 2)}

Six of the nine positive subjective effect items from cannabis use showed a significant trend towards younger athletes. These positive effects included help with sleep, calm, decreased anxiety, euphoria, decreased nausea, and increased energy. Less pain, fewer muscle spasms and improved athletic performance did not differ by age strata.

\section{Adverse subjective effects (Table 3)}

Adverse subjective effects were endorsed far less frequently than positive subjective effects; however, differences were noted by age strata. Significant trends for adverse effects were observed with higher endorsement for younger than older athletes for anxiety, increased appetite, cardiovascular (e.g. increased heart rate, palpitations), respiratory (e.g. wheezing, coughing, itchy eyes), gastrointestinal (e.g. vomiting, diarrhea, nausea), and poorer athletic performance.

\section{Discussion}

The present secondary analysis of a larger study (Zeiger et al. 2019a) examined patterns of cannabis use and subjective effects to cannabis by decade in adult community-based athletes. Significant differences were observed across decades for cannabis use patterns and reported subjective effects to cannabis. Younger athletes significantly used cannabis longer, consumed more THC only and in combination with CBD for recreational and combined medical/recreational purposes than older athletes. Younger athletes endorsed more positive and adverse subjective effects items than older athletes.

The different patterns of use and subjective effects to cannabis by age group in adults are novel findings since few studies have looked at specific age related effects to cannabis. A very small study reported that young adults ( $n=20,24-28$ years) reported more acute subjective effects (anxiety and less alertness) of inhaled cannabis than 20 adolescents (16-17 years) (Mokrysz et al. 2016). A cross-sectional study of adult users showed that older adults endorsed fewer positive and adverse subjective effects than younger adults, however older adults and those who used cannabis medically experienced the most acute withdrawal effects (Sexton et al. 2019). The difference in subjective effects to cannabis by age may stem from younger athletes consuming THC and THC/CBD combination more often than older athletes. An analysis of these data that explored the differences in subjective effects to cannabis by cannabinoid type suggested that athletes endorsed more positive and negative subjective effects to $\mathrm{THC} /$ CBD combination use (Zeiger et al. 2019c). The age related trends of subjective effects to cannabis may point to a biological difference in response to cannabis exposure in younger athletes or a willingness to use higher doses of THC via edibles or smoking, both of which can lead to a higher preponderance of positive and adverse effects which can sometimes lead to overdose (Meacham et al. 2018; Schauer et al. 2016; Monte et al. 2019). A study of medical cannabis users in California who were aged 18-72 found that younger users reported the highest quantity of use while older participants reported the fewest negative consequences related to cannabis use (Haug et al. 2017). Cohort effects of social acceptability, legal consequences, and legalization all may play a role in cannabis initiation, route of administration, and adoption of medical vs. recreation cannabis use (Haug et al. 2017). Although studies examining brain morphology have been disparate in their results, there is evidence that chronic cannabis users experience changes in brain structure and function, however it is unknown whether these changes are responsible for difference in subjective effects to cannabis by age (Lorenzetti et al. 2010; Batalla et al. 2013). Further studies need to be conducted in a larger replication sample and with clinical trials to better parse out the combined effects of THC and $\mathrm{CBD}$ and compare subjective and objective reactions to cannabis use by age. Reassuring of the clinical relevance of subjective effects, a recent trial found a moderate but statistically significant correlation between observed and self-reported subjective effects of intoxication between 
THC-only and low dose CBD in combination with THC (Solowij et al. 2019).

The use of cannabis to treat pain has been of interest. Less pain associated with cannabis use was reported from about 60 to $70 \%$ of athletes in all the age strata in the present study, highlighting that the reported positive effect of cannabis on reducing pain appears independent of age. The $69 \%$ frequency of pain relief in the present study across all ages is on the higher end of benefit reported in other studies noting an efficacy ranging from 37 to $86 \%$ for pain relief from cannabis (Ware et al. 2005; Brunt et al. 2014; Swift et al. 2005; Whiting et al. 2015).

Adverse effects were reported in this sample; however, at a lower reported rate than positive effects. Respiratory and cardiovascular adverse effects and anxiety showed the highest reporting in the younger age strata. This is possibly due to the route of administration since there was a tendency for the younger ages in this sample to smoke, vaporize, and consume edibles, while older age groups reported mostly using topicals, tinctures, and oils. Additionally, route of administration has been associated with subjective effects to cannabis use (Russell et al. 2018) and the preferred cannabinoids could also play a role in the reporting of adverse (and positive) effects (Niesink and van Laar 2013).

Our findings suggest that adult athletes are using cannabis both similarly and differently than adolescent and university athletes as well as the general population. Twenty-six percent of our overall sample reported current cannabis use, a frequency that is similar to that found in the NCAA, but lower than the overall population past-months use of $8.1 \%$ (Chawla et al. 2018). Past month use in a national sample showed lower frequencies of cannabis use across all ages than our sample of adult athletes (Chawla et al. 2018); national sample numbers ranged from $15.9 \%$ in $22-25$ years old's to $2.0 \%$ for those over 50. In our athlete sample, 33.3\% of 21 to 29 year old's consumed cannabis in the last 2 weeks, and 22.0 and $19.2 \%$ of those 50 to 59 and 60 and older used cannabis in the past 2 weeks, respectively.

The older adult athletes reported using cannabis for medical purposes with a preference for oral routes of administration, findings similar to other studies (Haug et al. 2017). Over $30 \%$ of this athlete sample reported using topical administration, a rate that is higher than reported in other studies (0.6-5\%) (Russell et al. 2018). The frequency of $32.9 \%$ medical-only cannabis use was higher in this sample than the $17 \%$ reported in the National Survey on Drug Use and Health (Green et al. 2003). Cross-use of medical and recreational cannabis was observed in $38.2 \%$ of our athletes, which is lower than the $55 \%$ of medical and recreational combination use seen in a survey of 348 medical cannabis users (Zeiger et al. 2012). Furthermore, medical patients use cannabis more frequently than our athlete population, with $75 \%$ reporting using cannabis more than once per day in published studies (Zuardi et al. 2017). Studies of cannabis use indicate that past-months use is higher in males than females (Chawla et al. 2018). Our sample skewed male (62.3\%), however, there were no significant differences by sex for current use.

It is challenging to put the results of the present study into the context of use in adolescent, university-based, and elite athletes. University athletes are mostly younger than the legal age for cannabis use and elite and university athletes are subjected to drug testing. However, drug testing among athletes is complicated by the fact that cannabis is a threshold drug, meaning athletes can use it out of competition up to a certain detectable blood THC level and THC is entirely banned within competition (Ware et al. 2018). The testing standards among elite athletes are different than occupational drug testing where any presence of cannabis may be grounds for discipline. Indeed, in our sample $20.5 \%$ of those who do not currently use cannabis reported they do not use it because it is not legal at their job. These complexities justify the importance of studying adult athletes apart from the traditional groups of adolescent, university, and elites.

Cannabis use concurrently with exercise was lower in this sample than the $81.7 \%$ found in a previous report, and unlike that study we did not find a difference by sex (data not shown); however, we did corroborate the finding that younger adults tended to use cannabis before and after exercise more often than older adults (YorkWilliams et al. 2019). In the previous study, the main reasons for cannabis use concurrent with exercise were enhanced performance, enjoyment, motivation, and recovery. In our study, we captured reasons for concurrent cannabis use with exercise separately for pre- and post- exercise; athletes in our study used cannabis for different reasons before exercise (improve focus, enjoyment) than after exercise (pain management, relaxation, aid in sleep). Our sample of athletes is unique in that $86.7 \%$ of participants indicated they exercise more than $5 \mathrm{~h}$ per week $(45.9 \%$ reported $\geq 11 \mathrm{~h}$ per week), a number that exceeds the $2.66 \mathrm{~h}$ per week of the concurrent cannabis users in the YorkWilliams study and the daily WHO recommendation of $1 \mathrm{~h}$ per day (Kahlmeier et al. 2015). Concerns about cannabis mis-use and abuse in athletes maybe overstated with the potential benefits (improved sleep, decreased anxiety, less pain) outweighing the adverse effects (increased anxiety, increased appetite, difficulty concentrating).

Several limitations exist. Questionnaire based studies are always subject to misclassification errors. The internal consistency of the responses lends credibility to the participants answers. A moderate but statistically significant correlation between observed and self-reported subjective effects of intoxication between THC and low dose $\mathrm{CBD}$ in combination with $\mathrm{THC}$ in a recent trial, 
results which are encouraging for self-reported data collection. (Solowij et al. 2019). The study did not ask about dosing or ratios of CBD and THC in those who used both CBD and THC which limits the specificity of this combination. The generalizability of this convenience sample drawn from social media outlets is unknown, particularly due to the over-representation of Caucasians. In addition, it is not known whether the age effects observed on cannabis use in athletes will be seen in non-athletes. The study of cannabis users was of moderate size, but confirmation in larger cohorts would be informative. These analyses are exploratory and do not correct for multiple testing; the results, however will inform future analyses with data reduction techniques that will enable multivariate analysis.

The strength of this study is the online recruitment of a relatively large sample in a short amount of time. Community-based adult athletes have been infrequently studied with respect to cannabis use, patterns of use, or subjective effects to cannabis (Campian et al. 2018). Most studies of cannabis use in athletes have been mainly in adolescents, university athletes, and elite athletes (Ware et al. 2018; Buckman et al. 2011; PerettiWatel et al. 2003a).

These analyses suggest there are age related differences in cannabis patterns of use and subjective effects to cannabis. The younger athletes compared to older athletes in this cohort reported more positive and adverse effects to cannabis, used cannabis longer, and consumed both CBD and THC for medical and recreational purposes. Future directions include examining age by cannabinoid type interactions in relation to subjective effects to cannabis.

\section{Additional files}

Additional file 1: Study questionnaire. (DOCX $21 \mathrm{~kb})$

Additional file 2: Table S1. Demographics and cannabis patterns of use by primary sport. (DOCX $27 \mathrm{~kb}$ )

Additional file 3: Table S2. Endorsement of reason for use within one hour before, during, and within one hour after exercise by age group. (DOCX $19 \mathrm{~kb}$ )

\section{Abbreviations}

CBD: Cannabidiol; THC: Tetrahydrocannabinol; The Athlete PEACE Survey: The Athlete Pain, Exercise, and Cannabis Experience Survey

\section{Acknowledgements}

We gratefully acknowledge the participants and those who shared our survey link.

\section{Authors' contributions}

JSZ was responsible for the conception of the study, study design, questionnaire development, participant recruitment, data analysis, manuscript preparation. EMF and WSS helped with study design, conceptualization and manuscript review. RSZ made substantial contribution to development of the questionnaire, interpretation of the data, and critical review of the manuscript. All authors read and approved the final manuscript.

\section{Funding}

The study was self-funded by the authors.

\section{Availability of data and materials}

The datasets used and/or analyzed during the current study are available from the corresponding author on reasonable request.

\section{Ethics approval and consent to participate}

This study was approved by Solutions, IRB with waived consent. Consent was given by filling out the survey.

\section{Consent for publication}

Not applicable.

\section{Competing interests}

The authors declare that they have no competing interests.

\section{Author details}

${ }^{1}$ Canna Research Group, 3996 Savannah Ct., Boulder, CO 80301, USA.

${ }^{2}$ Division of Allergy and Clinical Immunology, University of Colorado Denver School of Medicine, 12700 E. 19th Ave., Room 10C03, Aurora, CO 80045, USA.

${ }^{3}$ To-Life in Peace, LLC, 3812 Taft Court, Wheat Ridge, Colorado 80033, USA.

${ }^{4}$ Kaiser Permanente Southern California, 7060 Clairemont Mesa Blvd, San

Diego, CA 92111, USA.

Received: 11 April 2019 Accepted: 20 June 2019

Published online: 29 July 2019

\section{References}

Batalla A, Bhattacharyya S, Yücel M, Fusar-Poli P, Crippa JA, Nogué S, et al. Structural and functional imaging studies in chronic cannabis users: a systematic review of adolescent and adult findings. PLOS ONE. 2013;8: e55821. https://doi.org/10.1371/journal.pone.0055821

Bewick V, Cheek L, Ball J (2004) Statistics review 10: further nonparametric methods. Crit Care 8:196-199 https://doi.org/10.1186/cc2857. Accessed 28 Mar 2019.

Brisola-Santos MB, de M e GJG, Gil F, Sampaio-Junior B, Marin MCD, de Andrade $A G$, et al. Prevalence and correlates of cannabis use among athletes-a systematic review. Am J Addict. 2016;25:518-28. https://doi. org/10.1111/ajad.12425.

Brunt TM, van Genugten M, Höner-Snoeken K, van de Velde MJ, Niesink RJM. Therapeutic satisfaction and subjective effects of different strains of pharmaceutical-grade cannabis. J Clin Psychopharmacol. 2014;34:344-9. https://doi.org/10.1097/JCP.0000000000000129

Buckman JF, Yusko DA, Farris SG, White HR, Pandina RJ. Risk of marijuana use in male and female college student athletes and nonathletes. J Stud Alcohol Drugs. 2011;72:586-91 http://www.ncbi.nlm.nih.gov/pubmed/21683040. Accessed 7 Apr 2019.

Caine M, Blair K, Vasquez M (2012) Materials and technology in sport. doi:https:// doi.org/10.1038/nmat3382.

Campian MD, Flis AE, Teramoto M, Cushman DM. Self-reported use and attitudes toward performance-enhancing drugs in ultramarathon running. Wilderness Environ Med. 2018;29:330-7. https://doi.org/10.1016/J.WEM.2018.04.004.

Chawla D, Yang YC, Desrosiers TA, Westreich DJ, Olshan AF, Daniels JL. Pastmonth cannabis use among U.S. individuals from 2002-2015: an age-periodcohort analysis. Drug Alcohol Depend. 2018;193:177-82. https://doi.org/10. 1016/j.drugalcdep.2018.05.035

Conrad EC, Humphries S, Chatterjee A. Attitudes toward cognitive enhancement: the role of metaphor and context. AJOB Neurosci. 2019;10:35-47. https://doi. org/10.1080/21507740.2019.1595771.

Curran HV, Brignell C. Cognitive and subjective dose-response effects of acute oral $\Delta$ 9-tetrahydrocannabinol $(\mathrm{THC})$ in infrequent cannabis users practical use of the Glasgow coma scale; a comprehensive narrative review of GCS methodology view project thrombolysis and endovascular flow network (TEFLON) stroke trial view project. Psychopharmacology. 2002;164:61-70. https://doi.org/10.1007/s00213-002-1169-0.

Daniulaityte R, Zatreh MY, Lamy FR, Nahhas RW, Martins SS, Sheth A, et al. A twitter-based survey on marijuana concentrate use. Drug 
Alcohol Depend. 2018;187:155-9. https://doi.org/10.1016/j.drugalcdep. 2018.02.033.

Green B, Kavanagh D, Young R. Being stoned: a review of self-reported cannabis effects. Drug Alcohol Rev. 2003:453-60. https://doi.org/10.1080/ 09595230310001613976

Haberstick BC, Zeiger JS, Corley RP, Hopfer CJ, Stallings MC, Rhee SH, et al. Common and drug-specific genetic influences on subjective effects to alcohol, tobacco, and marijuana use. Addiction. 2011;106:215-24. https://doi. org/10.1111/j.1360-0443.2010.03129.x

Hainline B, Turner JA, Caneiro JP, Stewart M, Moseley GL. Pain in elite athletes-neurophysiological, biomechanical and psychosocial considerations: a narrative review. Br J Sport Med. 2017;51:1259-64. https:// doi.org/10.1136/BJSPORTS-2017-097890.

Halson SL. Sleep in elite athletes and nutritional interventions to enhance sleep. Sports Med. 2014;44(Suppl 1 Suppl 1):S13-23. https://doi.org/10.1007/s40279-014-0147-0.

Haug NA, Padula CB, Sottile JE, Vandrey R, Heinz AJ, Bonn-Miller MO. Cannabis use patterns and motives: a comparison of younger, middle-aged, and older medical cannabis dispensary patients. Addict Behav. 2017;72:14-20. https:// doi.org/10.1016/J.ADDBEH.2017.03.006.

Henry D, Dymnicki AB, Mohatt N, Allen J, Kelly JG. Clustering methods with qualitative data: a mixed-methods approach for prevention research with small samples. Prev Sci. 2015;16:1007-16. https:/doi.org/10.1007/s11121-015-0561-z.

Kahlmeier S, Wijnhoven TMA, Alpiger P, Schweizer C, Breda J, Martin BW. National physical activity recommendations: systematic overview and analysis of the situation in European countries. BMC Public Health. 2015;15:133. https://doi. org/10.1186/s12889-015-1412-3.

Lorenzetti V, Lubman DI, Whittle S, Solowij N, Murat A, Ucel Y". Structural MRI findings in long-term cannabis users: what do we know? Subst Use Misuse. 2010;45:1787-808. https://doi.org/10.3109/10826084.2010.482443.

Mann BJ, Grana WA, Indelicato PA, O'Neill DF, George SZ. A survey of sports medicine physicians regarding psychological issues in patient-athletes. Am J Sports Med. 2007;35:2140-7. https://doi.org/10.1177/0363546507304140.

Mannucci C, Navarra M, Calapai F, Spagnolo EV, Busardò FP, Cas RD, et al. Neurological aspects of medical use of cannabidiol. CNS Neurol Disord Drug Targets. 2017;16:541-53. https://doi.org/10.2174/ 1871527316666170413114210

Martin-Santos R, Crippa JA, Batalla A, Bhattacharyya S, Atakan Z, Borgwardt S, et al. (2012) Acute effects of a single, oral dose of d9-tetrahydrocannabinol (THC) and cannabidiol (CBD) administration in healthy volunteers. Curr Pharm Des 18:4966-4979 http://www.ncbi.nlm.nih.gov/pubmed/22716148. Accessed 31 Mar 2019.

Meacham MC, Paul MJ, Ramo DE. Understanding emerging forms of cannabis use through an online cannabis community: an analysis of relative post volume and subjective highness ratings. Drug Alcohol Depend. 2018;188: 364-9. https://doi.org/10.1016/j.drugalcdep.2018.03.041.

Mokrysz C, Freeman T, Korkki S, Griffiths K, Curran H. Are adolescents more vulnerable to the harmful effects of cannabis than adults? A placebocontrolled study in human males. Transl Psychiatry. 2016;6:e961 https://www. nature.com/articles/tp2016225. Accessed 28 Mar 2019.

Monte AA, Shelton SK, Mills E, Saben J, Hopkinson A, Sonn B, et al. Acute illness associated with cannabis use, by route of exposure. Ann Intern Med. 2019. https://doi.org/10.7326/M18-2809.

Niesink RJM, van Laar MW. Does cannabidiol protect against adverse psychological effects of THC? Front Psychiatry. 2013;4:130. https://doi.org/10.3389/fpsyt.2013.00130 .

Dolnicar S. Unquestioned standards in using cluster analysis for data-driven market segmentation. 2002. http.//ro.uow.edu.au/commpapers/273. Accessed 22 Apr 2019.

Peretti-Watel P, Guagliardo V, Verger P, Pruvost J, Mignon P, Obadia Y. Sporting activity and drug use: alcohol, cigarette and cannabis use among elite student athletes: Wiley; 2003a. https://hal-insep.archives-ouvertes.fr/hal01753448. Accessed 2 Jan 2019

Peretti-Watel P, Guagliardo V, Verger P, Pruvost J, Mignon P, Obadia Y. Sporting activity and drug use: alcohol, cigarette and cannabis use among elite student athletes. Addiction. 2003b;98:1249-56. https://doi.org/10.1046/j.13600443.2003.00490.x.

Russell C, Rueda S, Room R, Tyndall M, Fischer B. Routes of administration for cannabis use - basic prevalence and related health outcomes: a scoping review and synthesis. Int J Drug Policy. 2018;52:87-96. https://doi.org/10. 1016/j.drugpo.2017.11.008

Schauer GL, King BA, Bunnell RE, Promoff G, McAfee TA. Toking, vaping, and eating for health or fun marijuana use patterns in adults, U.S., 2014. Am J Prev Med. 2016;50:1-8. https://doi.org/10.1016/j.amepre.2015.05.027.
Scherrer JF, Grant JD, Duncan AE, Sartor CE, Haber JR, Jacob T, et al. Subjective effects to cannabis are associated with use, abuse and dependence after adjusting for genetic and environmental influences. Drug Alcohol Depend. 2009;105:76-82. https://doi.org/10.1016/j.drugalcdep.2009.06.014.

Schwope DM, Bosker WM, Ramaekers JG, Gorelick DA, Huestis MA. Psychomotor performance, subjective and physiological effects and whole blood D 9tetrahydrocannabinol concentrations in heavy, chronic Cannabis smokers following acute smoked Cannabis. J Anal Toxicol. 2012;36:405-12. https://doi. org/10.1093/jat/bks044.

Sexton M, Cuttler C, Finnell JS, Mischley LK. A cross-sectional survey of medical cannabis users: patterns of use and perceived efficacy. Cannabis Cannabinoid Res. 2016;1:131-8. https://doi.org/10.1089/can.2016.0007.

Sexton M, Cuttler C, Mischley LK. A survey of cannabis acute effects and withdrawal symptoms: differential responses across user types and age. J Altern Complement Med. 2019;25:326-35. https://doi.org/10.1089/acm.2018.0319

Solowij N, Broyd S, Greenwood L, van Hell H, Martelozzo D, Rueb K, et al. A randomised controlled trial of vaporised $\Delta$ 9-tetrahydrocannabinol and cannabidiol alone and in combination in frequent and infrequent cannabis users: acute intoxication effects. Eur Arch Psychiatry Clin Neurosci. 2019;269: 17-35. https://doi.org/10.1007/s00406-019-00978-2.

Stith SS, Vigil JM, Brockelman F, Keeling K, Hall B. Patient-reported symptom relief following medical cannabis consumption. Front Pharmacol. 2018;9:916. https://doi.org/10.3389/fphar.2018.00916

Stith SS, Vigil JM, Brockelman F, Keeling K, Hall B. The association between cannabis product characteristics and symptom relief. Sci Rep. 2019;9:2712. https://doi.org/10.1038/s41598-019-39462-1 .

Swift W, Gates P, Dillon P (2005) Survey of Australians using cannabis for medical purposes. Harm Reduct J 2:18 https://doi.org/10.1186/1477-7517-2-18. Accessed 28 Mar 2019.

Ware MA, Adams H, Guy GW. The medicinal use of cannabis in the UK: results of a nationwide survey. Int J Clin Pract. 2005;59:291-5.

Ware MA, Jensen D, Barrette A, Vernec A, Derman W. Cannabis and the health and performance of the elite athlete. Clin J Sport Med. 2018;28:480-4. https://doi.org/10.1097/JSM.0000000000000650.

Whiting P, Wolff R, Deshpande S, Di Nisio M, Duffy S, Hernandez A, et al. Cannabinoids for medical use: a systematic review and meta-analysis. Jama. 2015;313:2456-37 https://jamanetwork.com/journals/jama/fullarticle/ 2338251?utm_campaign=articlePDF\&utm_medium=articlePDFlink\&utm_ source=articlePDF\&utm_content=jama.2015.6358. Accessed $28 \mathrm{Mar} 2019$.

YorkWilliams SL, Gust CJ, Mueller R, Bidwell LC, Hutchison KE, Gillman AS, et al. The new runner's high? Examining relationships between cannabis use and exercise behavior in states with legalized cannabis. Front Public Heal. 2019;7: 99. https://doi.org/10.3389/fpubh.2019.00099.

Zeiger JS, Fleegler EM, Silvers WS, Zeiger RS. Cannabis use in active athletes: behaviors related to subjective effects. PLOS ONE. 2019a; June 28: 1-16. https://journals.plos.org/plosone/article?id=10.1371/journal.pone.0218998.

Zeiger JS, Haberstick BC, Corley RP, Ehringer MA, Crowley TJ, Hewitt JK, et al. Subjective effects to marijuana associated with marujuana use in community and clinical subjects. Drug Alcohol Depend. 2010;109:161-6. https://doi.org/ 10.1016/j.drugalcdep.2009.12.026.

Zeiger JS, Haberstick BC, Corley RP, Ehringer MA, Crowley TJ, Hewitt JK, et al. Subjective effects for alcohol, tobacco, and marijuana association with crossdrug outcomes. Drug Alcohol Depend. 2012;123:52-8. https://doi.org/10. 1016/j.drugalcdep.2012.02.014.

Zeiger JS, Silvers WS, Fleegler EM, Zeiger RS. Cannabis use for pain in a large population-based survey of adult athletes. In: Institute of Cannabis Research. Pueblo; 2019b. p. Abstract 5C.

Zeiger JS, Silvers WS, Fleegler EM, Zeiger RS. Cannabinoid use in a population based survey of adult athletes. Bethesda: International Cannabinoid Research Society; 2019c.

Zeiger JS, Zeiger RS. Mental toughness latent profiles in endurance athletes. PLoS One. 2018;13:e0193071. https://doi.org/10.1371/journal.pone.0193071.

Zuardi AW, Rodrigues NP, Silva AL, Bernardo SA, Hallak JEC, Guimarães FS, et al. Inverted U-shaped dose-response curve of the anxiolytic effect of Cannabidiol during public speaking in real life. Front Pharmacol. 2017;8:259. https://doi.org/10.3389/fphar.2017.00259.

\section{Publisher's Note}

Springer Nature remains neutral with regard to jurisdictional claims in published maps and institutional affiliations. 